\title{
Research into Making Yunnan a Pivot of China's Opening-up to South and Southeast Asia from the Perspective of "Growth Pole"
}

\author{
Piju Kang \\ International Business School \\ Yunnan University of Finance and Economics \\ Kunming, China \\ 1343681968@qq.com
}

\begin{abstract}
Making Yunnan a pivot of China's opening-up to South and Southeast Asia" is a strategy for the development of the current economy. From the "growth pole" theory, the construction has many problems such as weak economic strength, lagging infrastructure, and competition with Guangxi. Accelerating the economic development of Yunnan is the key to this issue. At present, air transportation can be as an alternative means to propel development.
\end{abstract}

Keywords: Yunnan, "growth pole", the pivot of China's

opening-up to South and Southeast Asia

\section{INTRODUCTION}

The visit by the General Secretary, Xi Jinping to Yunnan Province from January 19 to 21, 2015, saw him delivered an important speech and inspected ongoing works. In his speech, he expressed his desire for Yunnan to "actively serve and integrate into the national development strategy and pull along a path of leaping development, striving to become the demonstration area of national unity, the pacesetter of ecological civilization and the pivot of China's opening-up to South Asia and Southeast Asia."

The construction of the "pivot" has become a major task for Yunnan's economic and social development as it is seen as way to promote inclusive growth in Yunnan and its adjoining countries in South Asia and Southeast Asia. The development has led to an increase in research among academia. Cheng Yi, Liu Hui, Song Tao, Liu Haimeng, Tang Zhipeng and Zhan Dongsheng(2018) believe 'The level of foreign economic development in the southwestern region has changed from a relatively balanced pattern to a polarized one: the external economic development of Chengdu and Chongqing far exceeds that of other regions' [1]. Wu Lei and Cao Fengyu (2018) hold that 'further opening up to the outside world in Yunnan still have to break through the "double bottlenecks": One is the identity characteristics of the underdeveloped provinces in the west, and the other is the backward economic development level and its complicated geopolitical situation [2]. Author Cheng Lijun (2015) thinks the economic issue is the first for the region "pivot" of Yunnan opening-up South and Southeast Asia [3]. Scholars Hui Chunmei, Yang Zaifeng, Wang Zuoxin (2108) [4] and Shao Yuhua, Wang Yidong

(2016) have studied the issue from the perspective of logistic [5]. Other researches from some certain aspects include authors Zhu Li, Zhang Aihua, Cui Hengliang, Wang Ting (2018)[6] And Cheng Lijun(2018) [7].

However, there are still questions that need to be answered, which include; what is "pivot"? How is "pivot" built? Answers to these questions will provide clear guidelines to policy makers in their attempt to make Yunnan a pivot of China's opening-up to South and Southeast Asia.

The application of the principles of regional economics in the study of the "pivot" has not also received attention among researchers. This paper therefore seeks to find answers to the above questions by apply the principle of regional economics to study Yunnan as a "pivot' of China's opening-up to South and Southeast Asia.

\section{CONNOTATION AND THEORETICAL ANALYSIS ON "THE PIVOT OF CHINA'S OPENING-UP TO SOUTH ASIA AND SOUTHEAST ASIA"}

As part of plans to promote economic activities in Yunnan province, the government has initiated a concept of "pivot" for South Asia and Southeast Asia for the period 2016 to 2020. The main goal is to ensure that Yunnan province becomes a hub for aggregation, flow and spread of capitals, talents, technologies, information and promotion of market activities between China and Southeast Asian countries. The key tasks are to promote the construction of regional international centers of economy and trade, science and technology innovation, financial service, exchanges of human capital, comprehensively enhancing the economic influence, innovation driving power, human affinity and soft power of culture. The "pivot" is a comprehensive concept covering area such as economics, science, technology, culture, education and other aspects. The construction of "pivot" will not only emphasize on economy and trade, but economy and trade is the basis and key content of the construction. Without strong 
exchanges in economy and trade, there can be no in-depth exchanges in other aspects. This article explores how the "pivot" has promoted or will promote economic activities between South Asia and Southeast Asia.

The idea of economic Growth Poles was introduced by François Perroux in 1949. The core point is that economic development, or growth, is not uniform over an entire region, but instead takes place around a specific pole within an area where economic growth is concentrated. This growth may encourage further development in the surrounding area (through the multiplier effect), especially in areas of industrial decline or stagnation, such as assisted areas. This pole is often characterized by a key industry around which linked industries develop, mainly through direct and indirect effects. Growth poles are often towns, or parts of towns, that are gaining industry and expanding.

The theory of "growth pole" of regional economics explains the process from the perspective of economic development, which play an organizational role in regional economic activities through dominance, multiplier effects, planning, and diffusion effects [8]." From the perspective of regional economics, the "pivot" is to form a series of growth poles in Kunming and other large and medium-sized cities in Yunnan Province. From another perspective, if Yunnan is considered as a whole in South Asia and Southeast Asia, then Yunnan itself is a "pivot". The formation process of the growth pole is essentially the process of agglomeration, flow and diffusion of capital, talents, technology, information, market and other factors in this case between China and Southeast Asian countries. This will promote rational division of labor in the regional economy, which would then translate into the development of the whole region. So the concept "pivot" in this paper focuses on the following:

1) "Pivot" emphasizes the demonstration role of the region, that is, Yunnan province should drive the overall development of South Asia and Southeast Asia, especially the relatively underdeveloped countries in these regions, such as Myanmar, Laos in Southeast Asia, Pakistan, Bangladesh, Sri Lanka and Nepal in South Asia. The basis to establish Yunnan as the "pivot" is because of its relatively state of development in the region of South Asia and Southeast Asia. Based on its strong economy, the construction would propel the development of other South Asian and Southeast Asian countries.

2) The construction of "pivot" cannot simply regard those countries in South Asia and Southeast Asia as the export destination of commodities from Yunnan province. On the contrary, import trade and direct investment from South Asia and Southeast Asia can further promote Yunnan's development The "pivot" is a "hub area". From the perspective of economy and trade, it is right to say Yunnan province occupies a large proportion in trade, investment and foreign engineering contracting among China, South Asia and Southeast Asian countries.

\section{THE CURRENT SITUATION OF YUNNAN AS A PIVOT OF CHINA'S OPENING-UP TO SOUTH AND SOUTHEAST ASIA FROM THE PESPECTIVE OF TRADE}

The following is a list of trades between China and ten countries in ASEAN and seven in South Asia; Yunnan and ten countries in ASEAN and seven in South Asia.

Table 1 Trade between China and Yunnan against ASEAN countries Unit: 100 million US dollars

\begin{tabular}{|l|l|l|l|l|l|l|}
\hline $\begin{array}{l}\text { Area } \\
\text { Year }\end{array}$ & $\begin{array}{l}\text { Export } \\
\text { of China }\end{array}$ & $\begin{array}{l}\text { Export } \\
\text { of } \\
\text { Yunnan }\end{array}$ & $\begin{array}{l}\text { Ration } \\
\text { of } \\
\text { Yunnan }\end{array}$ & $\begin{array}{l}\text { Import } \\
\text { of China }\end{array}$ & $\begin{array}{l}\text { Import } \\
\text { of } \\
\text { Yunnan }\end{array}$ & $\begin{array}{l}\text { Ration } \\
\text { of } \\
\text { Yunnan }\end{array}$ \\
\hline $200 \overline{7}$ & 1062.58 & 15.19 & $1.43 \%$ & 1067.49 & 10.52 & $0.99 \%$ \\
\hline $2008 \backslash$ & 1381.61 & 29.01 & $2.10 \%$ & 1547.01 & 16.76 & $1.08 \%$ \\
\hline 2009 & 1770.7 & 35.49 & $2.00 \%$ & 1930.19 & 24.05 & $1.25 \%$ \\
\hline 2010 & 2042.53 & 29 & $1.42 \%$ & 1958.56 & 16.76 & $0.86 \%$ \\
\hline 2011 & 2440.41 & 35.49 & $1.45 \%$ & 1995.6 & 24.05 & $1.21 \%$ \\
\hline 2012 & 2720.46 & 36.76 & $1.35 \%$ & 2082.4 & 30.88 & $1.48 \%$ \\
\hline 2013 & 2440.41 & 67.45 & $2.76 \%$ & 1995.6 & 41.5 & $2.08 \%$ \\
\hline 2014 & 2720.46 & 87.23 & $3.21 \%$ & 2082.4 & 55.92 & $2.69 \%$ \\
\hline 2015 & 2772.91 & 82.42 & $2.97 \%$ & 1994.75 & 49.24 & $2.47 \%$ \\
\hline 2016 & 2560.68 & 61.26 & $2.39 \%$ & 1963.07 & 57.07 & $2.91 \%$ \\
\hline 2017 & 2795.02 & 67.27 & $2.41 \%$ & 2359.51 & 63.63 & $2.70 \%$ \\
\hline
\end{tabular}

Source: China Statistical Yearbook (2008-2018) Yunnan Statistical Yearbook ((2008-2018)

Table 2 China, Yunnan's trade with South Asian countries Unit: 100 million US dollars

\begin{tabular}{|l|l|l|l|l|l|l|}
\hline Area & $\begin{array}{l}\text { Export } \\
\text { of China }\end{array}$ & $\begin{array}{l}\text { Export } \\
\text { of } \\
\text { Yunnan }\end{array}$ & $\begin{array}{l}\text { Ration } \\
\text { of } \\
\text { Yunnan }\end{array}$ & $\begin{array}{l}\text { Import } \\
\text { of } \\
\text { China }\end{array}$ & $\begin{array}{l}\text { Import } \\
\text { of } \\
\text { Yunnan }\end{array}$ & $\begin{array}{l}\text { Ration } \\
\text { of } \\
\text { Yunnan }\end{array}$ \\
\hline $200 \bar{x}$ & 349.45 & 3.72 & $1.06 \%$ & 158.99 & 1.74 & $1.09 \%$ \\
\hline 2008 & 442.38 & 6.59 & $1.49 \%$ & 214.66 & 2.37 & $1.10 \%$ \\
\hline 2009 & 416.48 & 3.94 & $0.95 \%$ & 152.03 & 1.45 & $0.95 \%$ \\
\hline 2010 & 574.33 & 7.65 & $1.33 \%$ & 229.6 & 1.62 & $0.71 \%$ \\
\hline 2011 & 713.72 & 9.31 & $1.30 \%$ & 261.05 & 1.48 & $0.57 \%$ \\
\hline 2012 & 699.84 & 5.34 & $0.76 \%$ & 226.06 & 0.35 & $0.15 \%$ \\
\hline 2013 & 749.19 & 7.33 & $0.98 \%$ & 209.96 & 0.41 & $0.20 \%$ \\
\hline 2014 & 854.36 & 7.53 & $0.88 \%$ & 201.7 & 0.16 & $0.08 \%$ \\
\hline 2015 & 930.49 & 10.73 & $1.15 \%$ & 169.19 & 0.13 & $0.08 \%$ \\
\hline 2016 & 954.32 & 5.36 & $0.56 \%$ & 148.42 & 0.25 & $0.17 \%$ \\
\hline 2017 & 1068.19 & 5.22 & $0.49 \%$ & 193.82 & 0.56 & $0.29 \%$ \\
\hline
\end{tabular}

Source: China Statistical Yearbook (2008-2018) Yunnan Statistical Yearbook ((2008-2018)

The Tables 1 and 2 above present the results on Yunnan's exports to the ten ASEAN countries. In the past 10 years, export figures for most years were less than 3\%, indicating that Yunnan has not shown a comparative advantage in China's trade with ASEAN. The trends show that, since 2013, the Yunnan team's share of ASEAN trade has not increased significantly. In the same manner, Yunnan has recorded less than $1 \%$ in both exports and imports in its trade with the seven South Asia countries. The data from 2013 shows that trade between Yunnan province and its ASEAN counterparts recorded values of $2.75 \%$ and $2.57 \%$ for exports and imports, respectively. The trade however fair badly with its South Asian counterparts as it recorded values of $0.81 \%$ and $0.16 \%$ for export and imports, respectively. It must be emphasized that Yunnan as the "pivot" is still in its startup phase.

The following analyzes the situation of three countries bordering Yunnan. 
Table3 China, Yunnan's trade against Myanmar Unit: 100 million US dollars

\begin{tabular}{|c|c|c|c|c|c|c|}
\hline $\begin{array}{c}\text { Area } \\
\text { Year }\end{array}$ & $\begin{array}{c}\text { Export of } \\
\text { China }\end{array}$ & $\begin{array}{c}\text { Export } \\
\text { of } \\
\text { Yunnan }\end{array}$ & $\begin{array}{c}\text { Ration of } \\
\text { Yunnan }\end{array}$ & $\begin{array}{c}\text { Import } \\
\text { of China }\end{array}$ & $\begin{array}{c}\text { Import } \\
\text { of } \\
\text { Yunnan }\end{array}$ & $\begin{array}{c}\text { Ration } \\
\text { of } \\
\text { Yunnan }\end{array}$ \\
\hline 2007 & 17.00 & 6.41 & $37.69 \%$ & 3.78 & 2.33 & $61.59 \%$ \\
\hline 2008 & 19.78 & 7.28 & $36.79 \%$ & 6.48 & 4.65 & $71.82 \%$ \\
\hline 2009 & 22.54 & 7.75 & $34.39 \%$ & 6.46 & 4.52 & $70.00 \%$ \\
\hline 2010 & 34.76 & 11.10 & $31.95 \%$ & 9.67 & 6.49 & $67.17 \%$ \\
\hline 2011 & 48.22 & 14.00 & $29.03 \%$ & 16.80 & 6.72 & $39.99 \%$ \\
\hline 2012 & 56.74 & 15.29 & $26.95 \%$ & 12.98 & 7.43 & $57.23 \%$ \\
\hline 2013 & 73.39 & 24.35 & $33.18 \%$ & 28.57 & 17.38 & $60.84 \%$ \\
\hline 2014 & 93.68 & 34.68 & $37.02 \%$ & 156.01 & 35.79 & $22.94 \%$ \\
\hline 2015 & 96.51 & 25.02 & $25.93 \%$ & 54.49 & 33.39 & $61.27 \%$ \\
\hline 2016 & 81.89 & 24.89 & $30.40 \%$ & 40.98 & 35.76 & $87.27 \%$ \\
\hline 2017 & 89.48 & 27.01 & $30.18 \%$ & 45.26 & 36.09 & $79.73 \%$ \\
\hline
\end{tabular}

Source: China Statistical Yearbook (2008-2018) Yunnan Statistical Yearbook ((2008-2018)

Table 4 China, Yunnan's trade against Laos

Unit: 100 million US dollars

\begin{tabular}{|l|l|l|l|l|l|l|}
\hline $\begin{array}{l}\text { Area } \\
\text { Year }\end{array}$ & $\begin{array}{l}\text { Export of } \\
\text { China }\end{array}$ & $\begin{array}{l}\text { Export } \\
\text { of } \\
\text { Yunnan }\end{array}$ & $\begin{array}{l}\text { Ration of } \\
\text { Yunnan }\end{array}$ & $\begin{array}{l}\text { Import } \\
\text { of } \\
\text { China }\end{array}$ & $\begin{array}{l}\text { Import } \\
\text { of } \\
\text { Yunnan }\end{array}$ & $\begin{array}{l}\text { Ration of } \\
\text { Yunnan }\end{array}$ \\
\hline 2007 & 1.78 & 0.36 & $20.18 \%$ & 0.86 & 0.47 & $55.26 \%$ \\
\hline 2008 & 2.68 & 0.57 & $21.30 \%$ & 1.34 & 0.53 & $39.73 \%$ \\
\hline 2009 & 3.77 & 0.74 & $19.71 \%$ & 3.75 & 0.81 & $21.53 \%$ \\
\hline 2010 & 4.84 & 1.03 & $21.27 \%$ & 6.01 & 1.01 & $16.78 \%$ \\
\hline 2011 & 4.76 & 1.04 & $21.75 \%$ & 8.25 & 1.62 & $19.67 \%$ \\
\hline 2012 & 9.34 & 1.52 & $16.27 \%$ & 7.87 & 1.95 & $24.79 \%$ \\
\hline 2013 & 17.23 & 7.27 & $42.20 \%$ & 10.10 & 3.22 & $31.88 \%$ \\
\hline 2014 & 18.39 & 9.06 & $49.25 \%$ & 17.78 & 4.66 & $26.21 \%$ \\
\hline 2015 & 12.26 & 3.18 & $25.94 \%$ & 15.47 & 5.64 & $36.45 \%$ \\
\hline 2016 & 9.87 & 2.10 & $21.27 \%$ & 13.60 & 6.59 & $48.47 \%$ \\
\hline 2017 & 14.19 & 2.44 & $17.19 \%$ & 16.05 & 7.66 & $47.73 \%$ \\
\hline
\end{tabular}

Source: China Statistical Yearbook (2008-2018) Yunnan Statistical Yearbook ((2008-2018)
Table 5 China, Yunnan's trade against Vietnam Unit: 100 million US dollars

\begin{tabular}{|l|l|l|l|l|l|l|}
\hline Area & $\begin{array}{l}\text { Export } \\
\text { of China }\end{array}$ & $\begin{array}{l}\text { Export } \\
\text { of } \\
\text { Yunnan }\end{array}$ & $\begin{array}{l}\text { Ration } \\
\text { of } \\
\text { Yunnan }\end{array}$ & $\begin{array}{l}\text { Import } \\
\text { of } \\
\text { China }\end{array}$ & $\begin{array}{l}\text { Import } \\
\text { of } \\
\text { Yunnan }\end{array}$ & $\begin{array}{l}\text { Ration } \\
\text { of } \\
\text { Yunnan }\end{array}$ \\
\hline $200 \chi^{\prime}$ & 118.91 & 7.78 & $6.54 \%$ & 32.26 & 1.94 & 6.01 \\
\hline 2008 & 151.22 & 4.93 & $3.26 \%$ & 43.36 & 1.52 & $3.50 \%$ \\
\hline 2009 & 162.98 & 6.61 & $4.06 \%$ & 47.78 & 1.29 & $2.71 \%$ \\
\hline 2010 & 231.02 & 7.89 & $3.41 \%$ & 69.85 & 1.61 & $2.30 \%$ \\
\hline 2011 & 290.90 & 9.73 & $3.34 \%$ & 111.18 & 2.41 & $2.17 \%$ \\
\hline 2012 & 342.08 & 8.29 & $2.42 \%$ & 162.31 & 2.17 & $1.34 \%$ \\
\hline 2013 & 485.86 & 10.77 & $2.22 \%$ & 168.92 & 2.56 & $1.52 \%$ \\
\hline 2014 & 637.30 & 14.18 & $2.23 \%$ & 199.06 & 1.44 & $0.72 \%$ \\
\hline 2015 & 660.17 & 15.61 & $2.36 \%$ & 298.32 & 7.65 & $2.56 \%$ \\
\hline 2016 & 611.04 & 13.90 & $2.27 \%$ & 371.72 & 12.92 & $3.48 \%$ \\
\hline 2017 & 716.17 & 19.57 & $2.73 \%$ & 503.75 & 16.90 & $3.35 \%$ \\
\hline
\end{tabular}

Source: China Statistical Yearbook (2008-2018) Yunnan Statistical Yearbook ((2008-2018)

The Tables 3 and 4, present the results on specific countries, thus countries bordering with Yunnan; Myanmar, Laos and Vietnam. In the trade with ASEAN and South Asian countries, Myanmar and Laos have comparative advantages. However, these two countries only account for a small proportion of China's trade with ASEAN countries. Taking 2017 as an example, the proportion of Myanmar and Laos trade with China and ASEAN countries for export is $2.6 \%$ and $0.6 \%$, respectively.

The Table 5 shows that since 2007, both exports and imports have assumed a downward trend in the trade relationship between Yunnan and Vietnam. What's more, the trade between Yunnan and other South Asian countries--Bhutan, Maldives and Nepal from 2007 to 2017 was zero.

\section{PROBLEMS FACED BY YUNNAN AS A PIVOT OF CHINA'S OPENNING-UP TO SOUTH AND SOUTHEAST ASIA}

From the economic point of view, the major problems confronting the construction of making Yunnan a pivot of China's opening-up to South and Southeast Asia are:

The first problem has to do with Yunnan's weak economic strength and its weak radiation-driven ability based on the theory of growth poles. In 2018, the total GDP of Yunnan was 1.7881 trillion Yuan (Yunnan Statistical Bureau's "Statistical Communiqué on National Economic and Social Development of Yunnan in 2018"), which only accounts for 2.0\% of China's total GDP. Generally speaking, there is a strong correlation between the total GDP, imports and exports. The relatively low proportion of Yunnan's trade in South Asia and Southeast Asia in China is attributed to its small economic aggregate.

\section{Figure 1}

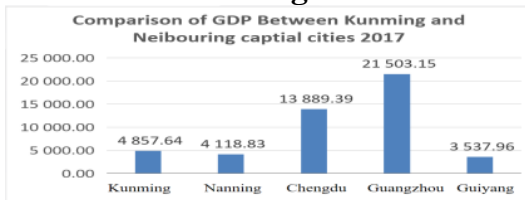

Source: Yunnan Statistical Yearbook ((2008-2018), Sichuan Statistical Yearbook (2008-2018) Guangxi Statistical Yearbook (2008-2018); Guangdong Statistical Yearbook ((2008-2018); Guizhou Statistical Yearbook ((2008-2018) 
Kunming is a key city for the construction of the "pivot" in Yunnan but its neighboring provinces such as Sichuan, Chongqing, Guizhou, Guangxi, and Guangdong also have location advantage in the opening-up to South and Southeast Asia countries with easy access to their markets. Kunming has no significant advantages compared with these provincial capitals because its GDP is only $35 \%$ and $22 \%$ of Chengdu and Guangzhou respectively, only slightly higher than Nanning, which makes it difficult to compete favorably with these provinces in trying to occupy Southeast Asia markets.

\section{Figure 2}

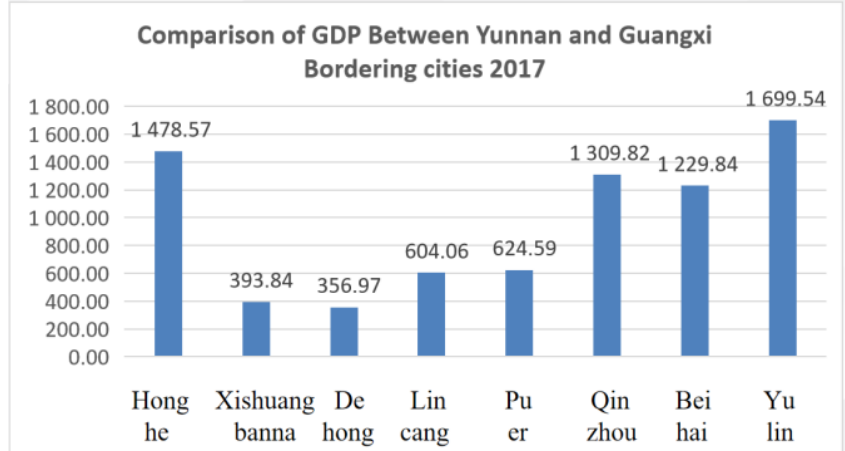

Source: Yunnan Statistical Yearbook ((2008-2018), Guangxi Statistical Yearbook (2008-2018)

Figure 3

\begin{tabular}{|c|c|c|c|c|}
\hline \multicolumn{5}{|c|}{$\begin{array}{l}\text { Comparison of GDP Beteen Yunnan and } \\
\text { Guangxi Developed cities } 2017\end{array}$} \\
\hline 3000.00 & & & & 2755.64 \\
\hline 2500.00 & & & & \\
\hline 2000.00 & & 1941.12 & 2045.18 & \\
\hline 1500.00 & 1415.14 & & & \\
\hline 1000.00 & & & & \\
\hline 500.00 & & & & \\
\hline 0.00 & Yuxi & Qujing & Guilin & Liuzhou \\
\hline
\end{tabular}

Source: Yunnan Statistical Yearbook ((2008-2018), Guangxi Statistical Yearbook (2008-2018)

From the perspective of border trade, except for Honghe, the total GDP of Xishuangbanna, Dehong, Linyi and Pu'er all in Yunnan province is much smaller than the cities of Qinzhou, Beihai and Yulin in Guangxi. Qujing and Yuxi in Yunnan province are relatively large cities, but their total economic output is also smaller than that in Guilin and Liuzhou in Guangxi. This shows that the economic power of Yunnan is still not strong enough to drive those countries in South and Southeast Asia.

Second, infrastructure construction is seriously lagging in Yunnan province. Although, in recent years Yunnan has experienced an increased in the construction of transportation infrastructure, there is still a huge gap to meet the requirements for its "pivot" responsibilities in terms of railways and highways to South Asia and Southeast Asia. The railway to Yunnan and Laos has been under construction, but it will take a longer period to be completed. The first phase of the Sino-Thai Railway Cooperation Project and the China-Laos Railway started in December 2017 and December 2016, respectively. The construction of the China-Myanmar railway has just started its preliminary work, and some domestic Yumo Railway and Darui Railway are still under construction. Although the expressway in Yunnan can meet the needs of cargo transportation, the road conditions in Laos and Myanmar are poor, which brings about high transportation costs and long transportation time. Even though Yunnan has made major strides in road infrastructure, it will take time for it to realize it full benefit as some of the projects are still under construction. These factors have fundamentally restricted its "pivot" role in China's opening-up to South and Southeast Asia. At least, in the short term it is impossible for Yunnan's location advantage to be transformed into an economic advantage.

Third, Yunnan and Guangxi have a strong competitive relationship in China's opening-up to South and Southeast Asia because of their good location advantages. In terms of transportation, the cost of shipping is low but it takes a longer time, and the railway transportation time is short but the cost is high. From this point of view, each has its own advantages. The railways from Yunnan to Myanmar, Laos and Thailand is yet to be in operation. However, the railway-sea transport combined under "China-Singapore (Chongqing) Strategic Interconnection Demonstration Project" from Chongqing through Guizhou and Guangxi from the Beibu Gulf is in operation. The "Overall Planning for the Western Land and Sea New Channel" by The National Development and Reform Commission has offered Guangxi more opportunities to open to Southeast Asia, which is a great challenge to build the "pivot" of Yunnan.

\section{POLICY PROPOSAL FOR THE CONSTRUCTION OF YUNNAN AS A PIVOT}

A) Speed up the construction of transportation infrastructure especially railways system, which is a major bottleneck in the construction of Yunnan as a "pivot" of China's opening-up to South and Southeast Asia. Greater attention should be paid to China-Myanmar railway, as it will serve as the most convenient route for Yunnan to open to the Indian Ocean and open to South Asia.

B) Accelerate economic development, promote the construction of region "pivot" of Yunnan, and form a mechanism for mutual promotion. It is necessary to maintain the economic growth rate of Yunnan at a level higher than the national average level, and promote the economic development of South Asia and Southeast Asia through the rapid development of Yunnan's overall economy, especially to accelerate the economic development of relatively developed cities such as Kunming, Qujing, Yuxi, Chuxiong and Dali. Accelerate economic development along the border areas such as Xishuangbanna, Dehong, Wenshan, etc., to create a "growth pole" and play a "diffusion effect". At the same time, more attention should be given to institutions and institutional innovations as it will create more convenient conditions for the flow of factors in Yunnan, South Asia and Southeast Asia: Increasing investment attraction, expanding Southeast Asia and South Asia markets, attracting eastern and central industries in 
China to Yunnan. Therefore, the economy of Yunnan's can develop rapidly through this big chance.

C) Third, at present it is particularly important to focus on air transportation as an alternative means to propel Yunnan's economic development, esp. some corresponding industries such as tourism and culture since Changshui International Airport has been running very smoothly with various international routes in South Asia and Southeast Asia.

\section{CONCLUSION}

The "Belt and Road" provides unlimited opportunities for the Yunnan's Economic development. Yunnan government strongly supported by Chinese central government should have clear idea of its strategic value of Yunnan's importance in China's opening-up to South and Southeast Asia. From the perspective of growth pole, Yunnan has to speed up its transportation infrastructure, esp. railways, promote the economic power of those vital cities-Kunming, Qujing, Yuxi, Dali, and create a good economic development environment to attract investment and industries. Currently, because location advantage of Yunnan is only reflected in air transportation, local government can accelerate the industry of tourism and culture to help Yunnan's economy development.

\section{REFERENCES}

[1] Cheng Yi, Liu Hui, Song Tao, Liu Haimeng Tang Zhipeng, Zhan Dongsheng: Spatio-temperal pattern and driving factors of foreign economic development in Southwest China, Vol. 27,No.4,Aug.,2018:7789

[2] Wu Lei, Cao Fengyu: Yunnan' s Opening to the Outside World: Historical Perspective, Bottlenecks and Solutions, Vo1. 44, No 3, 2018: 83-93,

[3] Chen Lijun: The Connotation and Countermeasures of Regional Pivot Construction of Yunnan,[J],Yunnan Social Science, 2015,06:1-6

[4] Hui Chunmei, Yang Zaifeng, Wang Zuoxin: Research on the Current Situation and Countermeasures of International Logistics of Yunnan' s Bonded Area,[J] Logistics Engineering and Management: 2018,06:3133 ,

[5] Shao Yuhua, Wang Yidong: Planning Railway Logistics Center Faced Southeast Asia Region in Yunnan Province, [J],Transportation Engineering and Information No. 4Vo1. 14Dec. 2016

[6] Zhu Li, Zhang Aihua, Cui Hengliang, Wang Ting: Investigation and Research on the Construction of Sports Radiation Center for South Asia and Southeast Asia in Yunnan Province,[J]Journal of Baoshan College : 2018,05, 96-100,

[7] Cheng Lijun: Study of Yunnan in Building China's Regional International Humanities Exchange Center Facing South Asia and Southeast Asia,[J] The Journal of South China Sea Studies, 2018, Mar., Vol. 4 No. 1,

[8] Wu Dianting: Regional Economics, [M], Science Press, Beijing, 2003,9 : 183-184 